\title{
Zinc supplementation of Friesian cows: Effect on chemical-nutritional composition and aromatic profile of dairy products
}

\author{
Andrea lanni, ${ }^{1}$ Denise Innosa, ${ }^{1}$ Camillo Martino, ${ }^{2}$ Lisa Grotta, ${ }^{1}$ Francesca Bennato, ${ }^{1}$ and Giuseppe Martino ${ }^{1 *}$ \\ ${ }^{1}$ Faculty of BioScience and Technology for Food, Agriculture and Environment, University of Teramo, Via Renato Balzarini 1, 64100 Teramo, Italy \\ ${ }^{2}$ Department of Veterinary Medicine, University of Perugia, Via S. Costanzo 4, 06126 Perugia, Italy
}

\section{ABSTRACT}

Zinc represents an essential microelement for several biochemical mechanisms. The body's inability to store zinc necessarily requires a constant dietary supply to avoid alteration of physiological functions. The aim of the present study was to investigate the effect of dietary enrichment with zinc on chemical-nutritional and aromatic properties of milk and cheese. Thirty commercial dairy cows, balanced for parity, milk production, and days in milk, were randomly assigned to 2 groups. The control group was fed with a conventional complete diet (22 kg of dry matter/animal per day), whereas the experimental group received a daily zinc supplementation of $60 \mathrm{mg}$ per $\mathrm{kg}$ of dry complete feed. During the experimental period, the milk yield was monitored and samples of milk and caciotta cheese were collected to obtain information about the chemical-nutritional composition and aromatic profile. Dietary zinc integration did not influence milk yield and composition, but induced a marked reduction of somatic cell count and improved the oxidative stability of ripened caciotta cheese. In both milk and cheese, the experimental group samples were characterized by a lower concentration of saturated fatty acids and an increase in oleic acid, vaccenic acid, and rumenic acid. The aromatic profile of dairy products was also positively affected by dietary zinc intake, with an increase in concentration of carboxylic acids, aldehydes, and esters. The present results suggest a positive role of zinc in improving animal health and nutraceutical properties of milk and corresponding cheese. Taking into account the analysis of volatile compounds, zinc dietary supplementation of dairy cows should contribute to the production of cheeses with interesting organoleptic properties, although more studies are necessary to confirm the consumer acceptability of these changes.

Received October 17, 2018.

Accepted December 20, 2018

*Corresponding author: gmartino@unite.it
Key words: zinc, fatty acid, oxidative stability, zincdependent enzyme, volatile compound

\section{INTRODUCTION}

Zinc is a ubiquitous element in cells and belongs to the family of transition metals, which have low ionization energies and different oxidation states. Zinc represents an essential component of several metalloenzymes (Coleman, 1998) and transcription factors, with relevant roles in the metabolism of essential nutrients in animals. Zinc also plays a relevant role in the stabilization of RNA, DNA, and ribosomes, is involved in insulin production, has antioxidant effects (Kloubert and Rink, 2015), is crucial for maintenance of integrity and the barrier function of skin, and is involved in the immune system (Bonaventura et al., 2015). Zinc is not stored in the animal body, so for that reason a constant dietary supply is necessary to avoid the onset of a wide range of pathological conditions, such as skin parakeratosis, reduction or cessation of growth, general debility, lethargy, and increased susceptibility to infection (Miller, 1970).

High-yielding animals require feeding strategies that guarantee the right contribution of all the necessary microelements, such as zinc, manganese, copper, cobalt, iodine, and selenium. The research on zinc has aroused much interest in both human and veterinary medicine, and in an attempt to provide a sufficient status of this microelement in both animals and humans, a wide range of supplements has been introduced, containing mostly inorganic zinc (oxide, sulfate). Studies on lambs indicate that zinc sulfate and zinc oxide $(\mathrm{ZnO})$ are similar in bioavailability (Kegley and Spears, 1992; Sandoval et al., 1997), and although the mode of action is unclear, research suggests that the feeding enrichment with certain organic forms of zinc can improve animal production responses if compared with those observed in ruminants that are supplemented only with inorganic zinc (Spears, 1996). The apparent Zn absorption from zinc methionine and $\mathrm{ZnO}$ was similar when fed to lambs affected by zinc deficiency (Spears, 1989), although the urinary excretion of the microelement 
tended to be lower in lambs fed zinc methionine, suggesting a higher zinc retention. In addition to the form in which the zinc is administered to animals, the dose also seems to have a direct effect on the absorption degree of the microelement; in fact, zinc absorption from some organic zinc sources appears to be higher with respect to inorganic zinc when supplemented at high concentrations. In this regard, Rojas et al. (1995) evidenced higher zinc concentrations in the kidney, liver, and pancreas of lambs supplemented with $360 \mathrm{mg}$ of zinc lysine $/ \mathrm{kg}$ of diet, in comparison with lambs that received zinc sulfate, $\mathrm{ZnO}$, or zinc methionine. Actually $\mathrm{ZnO}$ represents the predominant form in which $\mathrm{Zn}$ is used for the industrial preparation of animal feeds, although recently nano zinc oxide has been introduced with the aim to obtain better characteristics in terms of solubility and Zn availability, without causing toxicity (Singh et al., 2018).

With regard to ruminants, an adequate microelement bioavailability is of fundamental importance to support the ruminal fermentation mediated by the enzymatic activities of ruminal microbes, which directly contributes to the chemical-nutritional quality of milk and products derived from it. Ruminant products are the only foods to contain CLA and significant amounts of various other trans fatty acids (FA), especially monounsaturated isomers, which represent the only natural source of trans FA in the human diet (Doreau et al., 2016). Sonawane and Arora (1976) reported an increased microbial protein synthesis in vitro after incubating rumen fluid with additional $\mathrm{Zn}$ as $\mathrm{ZnCl}_{2}$ or $\mathrm{ZnSO}_{4}$. According to the authors, this response was due to the direct effect of $\mathrm{Zn}$ in increasing microbial enzymatic activities. The present study aimed to assess the effect of dietary $\mathrm{ZnO}$ supplementation on nutritional quality, FA composition, oxidative stability, and aromatic profile of milk and related caciotta cheeses obtained from dairy cows.

\section{MATERIALS AND METHODS}

\section{Experimental Design, Diets, and Sampling}

The experimental plan was performed according to Directive 2010/63/EU of the European Parliament (European Union, 2010) and Directive 86/609/EEC (European Economic Community, 1986), which deal with the protection of animals used for scientific purposes. In this study no animals were killed.

Thirty Friesian cows, homogeneous for age (42.5 \pm 3 mo; mean $\pm \mathrm{SD})$ and lactation days $(78 \pm 16 \mathrm{~d})$, were used in this study. Animals, all with a good state of health, were randomly divided into 2 groups of 15 cows
Table 1. Ingredients and composition of TMR administered to each animal of both group of study

\begin{tabular}{ll}
\hline Item & Value \\
\hline Ingredient of TMR & \\
Corn silage, \% & 24 \\
First cut, alfalfa hay, \% & 5 \\
Corn meal, \% & 3.5 \\
Soybean, meal, \% & 3.0 \\
Fine bran, \% & 3.1 \\
Barley, meal, \% & 1.8 \\
CaCO, $\%$ & 0.2 \\
Vitamins and minerals, \% & 0.5 \\
kg of DM/animal per day & 22.73 \\
Chemical composition of TMR & \\
DM, \% & 56.56 \\
CP, ${ }^{1} \%$ & 15.31 \\
Ether extract, ${ }^{1} \%$ & 2.98 \\
Ash, ${ }^{\%} \%$ & 5.27 \\
NDF, ${ }^{1} \%$ & 32.62 \\
ADF, $\%$ & 20.18 \\
Starch, ${ }^{1} \%$ & 26.93 \\
Zinc, ${ }^{1}$ mg/animal per day & $37(+59.1)^{2}$ \\
\hline
\end{tabular}

${ }^{1}$ On a DM basis.

${ }^{2}$ The amount of zinc added to the diet of the experimental group is shown in parentheses.

each: a control group (CG) and an experimental group (ZG) whose diet was supplemented with zinc. The cows were housed for the entire trial period in 2 separate areas of free housing with an access to an identical feeding area. The study was conducted for a period of $49 \mathrm{~d}$, in which all animals received about $22 \mathrm{~kg} /$ animal per day of DM of TMR whose composition, reported in Table 1, was defined taking into account the parameters reported in the 7th edition of Nutrient Requirements of Dairy Cattle (NRC, 2001). Samples of TMR were analyzed, according to AOAC methods (AOAC, 1990), for CP (CD; method 930.15), ether extract (method 920.39), crude fiber (method 962.09), and ash (method 942.05); detergent procedures reported by Van Soest et al. (1991) were used for the determination of NDF and ADF.

The CG received, in the form of "unifeed" and during the entire trial, a complete food formulated taking into account the nutritional needs of cows in mid-lactation, and guaranteeing each animal the daily zinc requirement of about $40 \mathrm{mg}$ per $\mathrm{kg}$ of dry complete feed. The ZG received the same complete food, formulated according to the same requirements and prepared in the same way, but enriching the daily ration of each cow with additional $60 \mathrm{mg}$ of zinc per $\mathrm{kg}$ of dry complete feed to obtain a total intake of about $100 \mathrm{mg} / \mathrm{kg}$. For the preparation of the rations, $\mathrm{ZnO}$ was used as a powder with a minimum content of $72 \%$ zinc, and the dose management was performed according to Regulation (EC) No. 1831/2003 of the European Parliament and 
of the Council of 22 September 2003 (European Commission, 2003) on additives for use in animal nutrition.

On d 49, the milk was collected separately for each group and manipulated in the same way during cheesemaking, according to the manufacturing protocol reported below. Bulk milk was pasteurized at $72 \pm 1.5^{\circ} \mathrm{C}$ for $3 \mathrm{~min}$, cooled to $38 \pm 1.5^{\circ} \mathrm{C}$, and transferred to a container with the addiction of starter bacteria (50 $\mathrm{g} / 100 \mathrm{~L}$ ) followed by acidification; Lactococcus lactis and DEM 3 (Lactococcus lactis subsp. lactis, Lactococcus lactis ssp. cremoris, Lactococcus lactis subsp. lactis biovar diacetylactis, Leuconostoc mesenteroides subsp. cremoris) and Streptococcus thermophilus (STA IDC15) starter cultures were used. Rennet $(75 \%$ of chymosin and $25 \%$ of pepsin; 1:18,000 strength; Clerici, Cadorago, Italy) was added $(15 \mathrm{~g} / 100 \mathrm{~kg})$ to the milk, and coagulation started after about $30 \mathrm{~min}$ of incubation. The curd was broken into small pieces with a size comparable to that of hazelnuts and portioned in aliquots of about $1 \mathrm{~kg}$, which were inserted in molds and kept at $50 \pm 1.5^{\circ} \mathrm{C}$ until the $\mathrm{pH}$ reached a value of $5.10 \pm 0.15$. After this, a $20 \% \mathrm{NaCl}$ water solution was used to salt the cheese in brine ( $1 \mathrm{~h} / \mathrm{kg}$ of cheese). Thereafter, the salted, fresh cheese was stored in the ripening room at a controlled temperature $\left(10 \pm 0.5^{\circ} \mathrm{C}\right)$ and a relative humidity of $85 \%$. To evaluate changes in the chemical composition and quality attributes due to ripening, sampling and analyses on caciotta cheese were carried out after $1\left(\mathbf{T}_{\mathbf{1}}\right)$ and $30\left(\mathbf{T}_{\mathbf{3 0}}\right)$ d from the cheesemaking. Samples, collected in triplicate from 3 different cheese-makings, were partly immediately analyzed and partly packed under vacuum and frozen at $-20^{\circ} \mathrm{C}$ until analysis.

\section{Chemical Analysis of Milk and Caciotta Cheese}

Chemical composition of milk (fat, protein, casein, lactose, and urea) was determined by MilkoScan FT 6000 (Foss Integrator IMT; Foss, Hillerød, Denmark), whereas SCC and total bacterial count (TBC) were performed using, respectively, the Fossomatic FC and the BactoScan FC (Foss). In cheese, the evaluation of $\mathrm{pH}, \mathrm{DM}$, total proteins, lipids, and ash were performed as previously described by Tofalo et al. (2015).

For the determination of total amount of zinc in milk and cheese, samples were first mineralized by dry incineration, then subjected to atomic absorption spectrophotometry using an air/acetylene flame (Nascentes et al., 2004). The determination of zinc was performed by referring to a calibration, and results were expressed in milligrams per kilogram.

Milk lipid fraction was extracted according to the AOAC official method (AOAC International, 2000), whereas in cheese, the extraction was performed as described by Domagała et al. (2010) by using a mix of chloroform and methanol (2:1, vol/vol). Trans-methylation of lipid extracts and separation of FAME was performed following the procedure reported by Castellani et al. (2017). Peak areas were quantified using ChromeCard software (Thermo Fisher Scientific, Waltham, $\mathrm{MA}$ ), and the relative value of each individual FA was expressed as a percentage of the total FA. The value of each FA was used to calculate the sum of SFA, MUFA, and PUFA. Taking into account the values associated with each FA, atherogenic and thrombogenic indices were calculated in milk and cheese using the formulas proposed by Ulbricht and Southgate (1991); the desaturation index was calculated as proposed by Mele et al. (2007).

\section{Evaluation of Lipid Oxidation in Cheese by Thiobarbituric Acid Reactive Substance Test}

Fat oxidation was evaluated by measuring thiobarbituric acid reactive substances (TBARS). The analysis was performed according to the procedure reported by Grotta et al. (2017). For each sample, an aliquot of 5 $\mathrm{g}$ of frozen cheese was mixed, within 2 min of sample withdrawal from the freezer, with $500 \mu \mathrm{L}$ of $0.1 \%$ of butylated hydroxytoluene in methanol to stop the oxidation process. The mixture was homogenized with Ultra Turrax T-25 high speed homogenizer (IKA, Staufen, Germany) in $50 \mathrm{~mL}$ of an aqueous solution of $7 \%$ trichloroacetic acid, and then subjected to distillation. An aliquot of $2 \mathrm{~mL}$ of each distillate was mixed with an equal volume of a $0.02 M$ thiobarbituric acid (TBA) solution in $90 \%$ acetic acid. The solution was kept for one hour in a thermostated bath at $80^{\circ} \mathrm{C}$, and only after cooling, the absorbance at $534 \mathrm{~nm}$ was evaluated with a spectrophotometer (Jenway $6305 \mathrm{UV} / \mathrm{vis,} \mathrm{Jenway,}$ Essex, UK). The amount of malondialdehyde (MDA) of each sample was calculated by using a calibration curve, and results were expressed in micrograms of MDA per gram of cheese.

\section{Volatile Compound Analysis}

Extraction of volatile compounds (VOC) from milk and cheese samples was performed by solid-phase microextraction, and GC-MS analysis was performed with a gas chromatograph (Clarus 580, Perkin Elmer, Waltham, MA) coupled with a mass spectrometer (SQ8S, Perkin Elmer). The gas chromatograph was equipped with an Elite-5MS column (length $\times$ internal diameter: $30 \times 0.25 \mathrm{~mm}$; film thickness: $0.25 \mu \mathrm{m}$; Perkin Elmer). Five grams of previously grated cheese was mixed with $10 \mathrm{~mL}$ of saturated $\mathrm{NaCl}$ solution $(360$ $\mathrm{g} / \mathrm{L}$ ), then $10 \mu \mathrm{L}$ of internal standard solution (4-meth- 
yl-2-heptanone; $10 \mathrm{mg} / \mathrm{kg}$ in ethanol) was added. The vials were sealed with a polytetrafluoroethylene-silicone septum (Supelco, Bellefonte, PA) and stirred at $60^{\circ} \mathrm{C}$; VOC were extracted from the headspace with a divinylbenzene-carboxen-polydimethylsiloxane solid-phase microextraction fiber (length: $1 \mathrm{~cm}$; film thickness: 50/30 $\mu \mathrm{m}$; Supelco) with an exposition time of $60 \mathrm{~min}$. After adsorption time, the extracted VOC were thermally desorbed into the gas chromatograph injector splitless mode for $1 \mathrm{~min}$ at $250^{\circ} \mathrm{C}$. The oven temperature was held at $50^{\circ} \mathrm{C}$ for $1 \mathrm{~min}$, increased at a rate of $3^{\circ} \mathrm{C} / \mathrm{min}$ up to $200^{\circ} \mathrm{C}$ and held for $1 \mathrm{~min}$, and then increased from $200^{\circ} \mathrm{C}$ to $250^{\circ} \mathrm{C}$ at $15^{\circ} \mathrm{C} / \mathrm{min}$ and held for $15 \mathrm{~min}$. Helium was used as a carrier gas at a flow rate of $1 \mathrm{~mL} /$ min. The mass spectrometer operated in electronic impact ionization mode at $70 \mathrm{eV}$, and data were collected in full scan mode, with a scan time of $0.2 \mathrm{~s}$ over a mass range of 35 to 350 . Source and interface temperature were held at $250^{\circ} \mathrm{C}$. Volatile compounds were identified by comparison with mass spectra of a library database (NIST Mass Spectral library, Search Program version 2.0, National Institute of Standards and Technology, US Department of Commerce, Gaithersburg, MD) and by comparing the eluting order with Kovats indices.

\section{Evaluation of Physical Properties of Cheese by Texture Profile Analysis}

In this work, the texture analysis was performed in a texturometer TA-Xt2i (Stable Micro Systems, Surrey, UK), with a load cell of $5 \mathrm{~kg}$, by carrying out texture profile analysis. Before texture profile analysis, a layer of $0.5 \mathrm{~cm}$ was removed from the upper surface of the cheese to obtain a regular surface to probe penetration. Penetration tests were performed at $20 \pm 2^{\circ} \mathrm{C}$ using a plastic cylindrical probe of $13 \mathrm{~mm}$, a penetration depth of $20 \mathrm{~mm}$, and $1 \mathrm{~mm} / \mathrm{s}$ of crosshead speed. This test was done 5 times on each sample ( 1 on the middle and 4 on different parts of the cheese surface) and performed in triplicate. Four parameters were considered: hardness (force necessary to attain a given deformation), cohesiveness, gumminess, and resilience. The interpretation of these texture parameters was made according to Armero and Collar (1997).

\section{Statistical Analysis}

Statistical data processing was performed by the GLM procedure (Nelder and Baker, 1972) of the statistical package SPSS 13.0 (SPSS Inc., Chicago, IL), using a 1-way ANOVA considering the effect of food treatment as a factor of variation. When the variance analysis was significant $(P<0.05)$, the differences between the means were compared by the least significant difference test.

\section{RESULTS}

\section{Chemical-Nutritional Composition of Milk and Cheese}

Taking into account the milk production over the entire duration of the dietary zinc enrichment, no significant differences were evidenced between the 2 groups, reflecting the fact that such parameter was not affected by diet and diet-period interaction $(P<0.05)$. With regard to the chemical quality of milk (Table 2), none of the analyzed parameters underwent variation. Similarly, no significant differences were observed with regard to the ureic content, $\mathrm{TBC}$, and $\mathrm{pH}$, whereas the ZG samples showed a lower SCC compared with the CG $(P<0.05)$. With regard to the amount of zinc, higher average values were observed in the experimental group, though not significant.

Table 2. Milk yield and chemical composition of milk obtained from the control group (CG) and zinc group $(\mathrm{ZG})^{1}$

\begin{tabular}{|c|c|c|c|}
\hline \multirow[b]{2}{*}{ Item } & \multicolumn{2}{|c|}{ Diet } & \multirow[b]{2}{*}{$P$-value } \\
\hline & CG & $\mathrm{ZG}$ & \\
\hline Milk yield, $\mathrm{kg}$ & $39.21 \pm 1.45$ & $38.53 \pm 1.17$ & NS \\
\hline Fat, \% & $3.71 \pm 0.27$ & $3.32 \pm 0.21$ & NS \\
\hline Protein, \% & $3.06 \pm 0.07$ & $3.05 \pm 0.05$ & NS \\
\hline Casein, \% & $2.40 \pm 0.05$ & $2.40 \pm 0.04$ & NS \\
\hline Lactose, \% & $4.79 \pm 0.05$ & $4.85 \pm 0.03$ & NS \\
\hline Urea, mg/100 mL & $23.34 \pm 0.76$ & $22.94 \pm 0.62$ & NS \\
\hline $\mathrm{SCC}, \times 10^{3}$ cells $/ \mathrm{mL}$ & $416 \pm 44$ & $275 \pm 36$ & $*$ \\
\hline $\mathrm{TBC}, \mathrm{cfu} / \mathrm{mL} \cdot 10^{3}$ & $53 \pm 11$ & $48 \pm 9$ & NS \\
\hline $\mathrm{pH}$ & $6.67 \pm 0.02$ & $6.66 \pm 0.01$ & NS \\
\hline Zinc, mg/kg & $4.00 \pm 0.20$ & $4.12 \pm 0.18$ & NS \\
\hline
\end{tabular}


Table 3. Chemical composition of cheese obtained from the control group (CG) and zinc group (ZG), analyzed at $1\left(\mathrm{~T}_{1}\right)$ and $30\left(\mathrm{~T}_{30}\right)$ d after ripening $^{1}$

\begin{tabular}{|c|c|c|c|c|c|}
\hline Item & \multicolumn{2}{|c|}{$\mathrm{T}_{1}$} & \multicolumn{2}{|c|}{$\mathrm{T}_{30}$} & $P$-value \\
\hline$\overline{\mathrm{DM}}, \%$ & $55.07^{\mathrm{A}} \pm 4.03$ & $52.99^{\mathrm{A}} \pm 4.11$ & $65.97^{\mathrm{B}} \pm 5.54$ & $64.33^{\mathrm{B}} \pm 5.13$ & $*$ \\
\hline Protein, ${ }^{2} \%$ & $38.81 \pm 3.19$ & $42.93 \pm 3.75$ & $39.43 \pm 2.91$ & $42.64 \pm 3.16$ & NS \\
\hline $\mathrm{Ash}^{2} \%$ & $5.85 \pm 0.55$ & $6.25 \pm 0.58$ & $5.82 \pm 0.51$ & $5.89 \pm 0.48$ & NS \\
\hline Zinc, $\mathrm{mg} / \mathrm{kg}$ & $65.19 \pm 4.96$ & $75.28 \pm 6.63$ & $65.97 \pm 5.22$ & $69.17 \pm 5.68$ & NS \\
\hline
\end{tabular}

$\overline{\mathrm{A}, \mathrm{B}}$ Means with different superscripts are significantly different by ripening time.

${ }^{1}$ Data are expressed as mean $\pm \mathrm{SD}$.

${ }^{2}$ Data are expressed on a DM basis.

$* P<0.05$.

As evidenced for milk, the diet supplementation did not influence cheese yield $(P>0.05)$. Regardless of the feeding strategy, no significant differences $(P>$ 0.05 ) in composition of cheeses were observed (Table 3). Regarding the ripening time, the $\mathrm{DM}$ in $\mathrm{T}_{30}$ samples was significantly higher (65.97 vs. $55.07 \%$ in CG and 64.33 vs. $52.99 \%$ in ZG samples; $P<0.01$ ). Protein, lipids, and ash were not influenced by ripening, as well as the zinc amount, which maintained higher, but not significant, values in the ZG with respect to the $\mathrm{CG}$. Regarding the zinc amount, no differences were evidenced both in reference to the feeding strategy and the ripening time.

\section{Acidic Profile and Lipid Oxidation}

The FA composition of milk and corresponding dairy products is reported in Table 4. Samples of bulk milk, obtained from ZG, evidenced an increase in the content of oleic acid (C18:1 cis-9; $P<0.05)$, vaccenic acid (C18:1 trans-11; $P<0.01)$, linoleic acid (C18:2n-6; $P$ $<0.05$ ), and rumenic acid (CLA; $P<0.01$ ). Similarly, the evaluation of the acidic profile in cheese evidenced modifications already evident in milk, with an increase in concentration, in ZG, of oleic acid (C18:1 cis-9; $P$ $<0.05)$, vaccenic acid (C18:1 trans; $P<0.05)$, and rumenic acid (CLA; $P<0.05)$. Based on the obtained FA profile, calculations of atherogenic, thrombogenic, and desaturation indices were performed, highlighting a general improvement of nutritional value and health functionality of milk and cheese. Atherogenic and thrombogenic indices were lower in ZG $(P<0.05)$, whereas an increase in desaturation index was observed $(P<0.05)$.

An interesting finding of the experimentation is certainly due to the determination of the oxidative state of cheese after 1 and $30 \mathrm{~d}$ of ripening after cheesemaking. As can be seen in Figure 1, the levels of MDA significantly increased in CG samples after $30 \mathrm{~d}$ from the cheese-making (0.054 vs. $0.074 \mu \mathrm{g}$ of $\mathrm{MDA} / \mathrm{g} ; P$ $<0.05$ ), whereas the ZG samples underwent a slight reduction in the MDA content at the end of ripening, although this variation was not significant. It is important to strongly consider the fact that at the beginning of the ripening, the amount of the oxidation products ( $\mu \mathrm{g}$ of $\mathrm{MDA} / \mathrm{g}$ of cheese) in the ZG was about 2 times higher than the control $(P<0.01)$.

\section{Aromatic Profile of Cheese}

Several chemical families of VOC were detected in samples of $T_{1}$ cheese and $T_{30}$ cheese obtained from $C G$ and ZG (Table 5). The majority of the identified compounds consists of free fatty acids (FFA), aldehydes, alcohols, esters, lactones, and ketones, testifying the prevalence of lipolytic catabolism with respect to the proteolytic event.

Regarding the $\mathrm{CG}$, the results highlighted an increase $(P<0.05)$ of FFA, esters, lactones, and ketones during aging, whereas a reduction $(P<0.01)$ was observed in the case of aldehydes, alcohols, and aromatic hydrocarbons. In the case of $\mathrm{ZG}$ the condition is quite different; FFA, aldehydes, and aromatic hydrocarbons increased $(P<0.05)$ after $30 \mathrm{~d}$ of aging and alcohols decreased $(P<0.01)$, whereas no ripening effect was observed for esters, lactones, and ketones, whose concentrations did not differ significantly.

Comparing the results between the 2 groups, the FFA are present in higher concentration in CG in the $\mathrm{T}_{1}$ samples $(P<0.01)$ and this condition unchanged after $30 \mathrm{~d}$ of aging. Aldehydes, alcohols, lactones, and ketones did not differ significantly between the 2 groups in $\mathrm{T}_{1}$ samples; however, after ripening the aldehydes increased $(P<0.01)$ in the $\mathrm{ZG}$, whereas the other compounds were present in higher concentrations in the CG samples. Lastly, aromatic hydrocarbons were higher in the CG at $\mathrm{T}_{1}(P<0.01)$ whereas in the ZG this occurred after $30 \mathrm{~d}$ of aging $(P<0.01)$. 


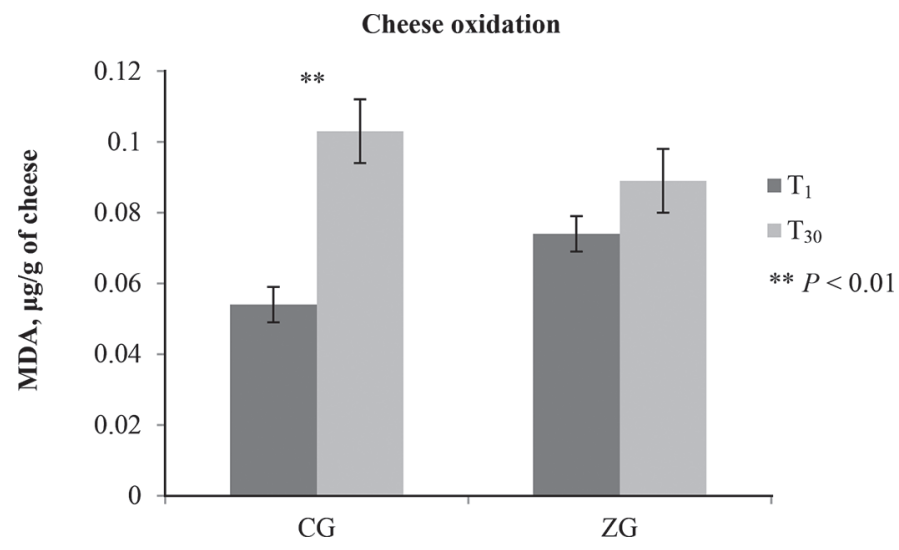

Figure 1. Oxidation profile of cheese samples obtained from the control group (CG) and the zinc group (ZG). Analysis performed on samples obtained after $1\left(\mathrm{~T}_{1}\right)$ and $30\left(\mathrm{~T}_{30}\right)$ d from the cheese-making. $\mathrm{MDA}=$ malondialdehyde. Data are expressed as mean $\pm \mathrm{SD}$.

\section{Texture Profile Analysis}

The analysis of cheese texture (Table 6) showed interesting and significant differences between samples obtained from the 2 different feeding strategies. Regarding hardness, ZG samples showed higher values compared with $\mathrm{CG}$ samples both at the beginning and at the end of ripening (4.91 N vs. $6.76 \mathrm{~N}$ for $\mathrm{CG}$ and $\mathrm{ZG}$, respectively, at $\mathrm{T}_{1} ; P<0.01$, and $6.27 \mathrm{~N}$ vs. $8.03 \mathrm{~N}$ for $\mathrm{CG}$ and $\mathrm{ZG}$, respectively, at $\mathrm{T}_{30} ; P<0.05$ ). Gumminess did not show significant differences at the beginning of the ripening between the 2 study groups, whereas at $T_{30}$ a significant reduction of this parameter was induced by the dietary zinc intake $(8.94 \mathrm{~N}$ vs. 6.03 $\mathrm{N}$ for $\mathrm{CG}$ and $\mathrm{ZG}$, respectively; $P<0.05$ ). The Young modulus showed significant differences only at $\mathrm{T}_{0}(1.55$ $\mathrm{MPa}$ vs. $2.39 \mathrm{MPa}$ for $\mathrm{CG}$ and $\mathrm{ZG}$, respectively; $P<$ $0.05)$, whereas no variation emerged from the analysis of cohesiveness.

\section{DISCUSSION}

Dietary Zn supplementation did not affect milk yield, in agreement with the results obtained by Pechová et al. (2006) that explored the effect of Zn supplementation on dairy cows, at a dose of $440 \mathrm{mg}$ per animal per day. The same authors, as in our case, reported also a significant reduction in the SCC value in the experimental group, justifying this phenomenon with an increased Zn supply into the mammary gland with a consequent improvement of the immune function and reduction of somatic cell release in milk. The feeding strategy based on zinc supplementation did not affect milk composition in the present study, and this finding is consistent with the previous reports in dairy cows (Cope et al., 2009; Wang et al., 2013) and dairy goats (Salama et al., 2003), indicating that milk composition was not sensitive in response to dietary Zn supplementation. A result on which it is necessary to focus attention concerns the zinc content, which did not change be-

Table 4. Acidic profile of bulk milk and related cheeses obtained from the control group $(\mathrm{CG})$ and zinc group $(\mathrm{ZG})^{1}$

\begin{tabular}{|c|c|c|c|c|c|c|}
\hline \multirow[b]{2}{*}{ Item } & \multicolumn{3}{|c|}{ Bulk milk } & \multicolumn{3}{|c|}{ Cheese } \\
\hline & $\mathrm{CG}$ & $\mathrm{ZG}$ & $P$-value & $\mathrm{CG}$ & $\mathrm{ZG}$ & $P$-value \\
\hline $\mathrm{C} 4: 0$ & $2.25 \pm 0.24$ & $2.72 \pm 0.26$ & NS & $2.33 \pm 0.26$ & $1.98 \pm 0.22$ & NS \\
\hline C6:0 & $2.01 \pm 0.21$ & $2.36 \pm 0.25$ & NS & $1.83 \pm 0.19$ & $1.67 \pm 0.18$ & NS \\
\hline C8:0 & $1.33 \pm 0.15$ & $1.71 \pm 0.19$ & NS & $1.57 \pm 0.17$ & $1.36 \pm 0.15$ & NS \\
\hline C10:0 & $2.09 \pm 0.22$ & $2.02 \pm 0.23$ & NS & $2.52 \pm 0.22$ & $2.83 \pm 0.26$ & NS \\
\hline C12:0 & $3.96 \pm 0.38$ & $3.56 \pm 0.32$ & NS & $3.71 \pm 0.31$ & $3.98 \pm 0.37$ & NS \\
\hline C14:0 & $13.21 \pm 1.23$ & $11.88 \pm 1.37$ & NS & $12.77 \pm 1.06$ & $11.97 \pm 1.21$ & NS \\
\hline C14:1 & $1.44 \pm 0.15$ & $1.98 \pm 0.21$ & NS & $1.62 \pm 0.17$ & $2.05 \pm 0.19$ & NS \\
\hline C15:0 & $1.31 \pm 0.15$ & $1.66 \pm 0.17$ & NS & $1.59 \pm 0.15$ & $1.48 \pm 0.15$ & NS \\
\hline C16:0 & $39.66 \pm 3.35$ & $34.40 \pm 3.04$ & NS & $40.37 \pm 3.67$ & $36.16 \pm 3.21$ & NS \\
\hline C16:1 & $1.87 \pm 0.19$ & $2.22 \pm 0.21$ & NS & $1.79 \pm 0.16$ & $1.91 \pm 0.18$ & NS \\
\hline $\mathrm{C} 17: 0$ & $0.52 \pm 0.07$ & $0.68 \pm 0.08$ & NS & $0.63 \pm 0.08$ & $0.77 \pm 0.08$ & NS \\
\hline C18:0 & $7.32 \pm 0.69$ & $6.48 \pm 0.61$ & NS & $8.61 \pm 0.71$ & $8.22 \pm 0.63$ & NS \\
\hline C18:1 trans-11 & $0.46 \pm 0.05$ & $0.82 \pm 0.09$ & $* *$ & $0.37 \pm 0.05$ & $0.69 \pm 0.08$ & $*$ \\
\hline $\mathrm{C} 18: 1$ cis-9 & $19.55 \pm 1.42$ & $22.95 \pm 1.69$ & $*$ & $16.89 \pm 1.52$ & $20.93 \pm 1.71$ & $*$ \\
\hline $\mathrm{C} 18: 1$ cis -11 & $0.38 \pm 0.05$ & $0.51 \pm 0.05$ & NS & $0.42 \pm 0.05$ & $0.55 \pm 0.06$ & NS \\
\hline $\mathrm{C} 18: 2$ & $1.75 \pm 0.16$ & $2.91 \pm 0.26$ & $*$ & $2.01 \pm 0.18$ & $2.17 \pm 0.19$ & NS \\
\hline $\mathrm{C} 18: 3$ & $0.48 \pm 0.06$ & $0.57 \pm 0.07$ & NS & $0.56 \pm 0.07$ & $0.66 \pm 0.07$ & NS \\
\hline CLA & $0.26 \pm 0.03$ & $0.54 \pm 0.06$ & $* *$ & $0.29 \pm 0.03$ & $0.46 \pm 0.06$ & $*$ \\
\hline C20:4 & $0.15 \pm 0.02$ & $0.23 \pm 0.03$ & NS & $0.12 \pm 0.02$ & $0.16 \pm 0.03$ & NS \\
\hline Atherogenic index & $3.76 \pm 0.28$ & $2.84 \pm 0.22$ & $*$ & $4.17 \pm 0.37$ & $3.40 \pm 0.29$ & $*$ \\
\hline Thrombogenic index & $4.35 \pm 0.36$ & $3.14 \pm 0.27$ & $*$ & $4.81 \pm 0.41$ & $3.68 \pm 0.33$ & $*$ \\
\hline Desaturation index & $0.11 \pm 0.01$ & $0.16 \pm 0.01$ & $*$ & $0.13 \pm 0.01$ & $0.17 \pm 0.01$ & $*$ \\
\hline
\end{tabular}

${ }^{1}$ Data are expressed as mean \pm SD. Fatty acids are expressed as percent of total fatty acids. CLA $=$ rumenic acid.

${ }^{*} P<0.05 ; * * P<0.01$. 
Table 5. Volatile compounds (VOC) detected in cheese samples after $1\left(\mathrm{~T}_{1}\right)$ and $30\left(\mathrm{~T}_{30}\right)$ d obtained from the control group (CG) and zinc group $(\mathrm{ZG})^{1}$

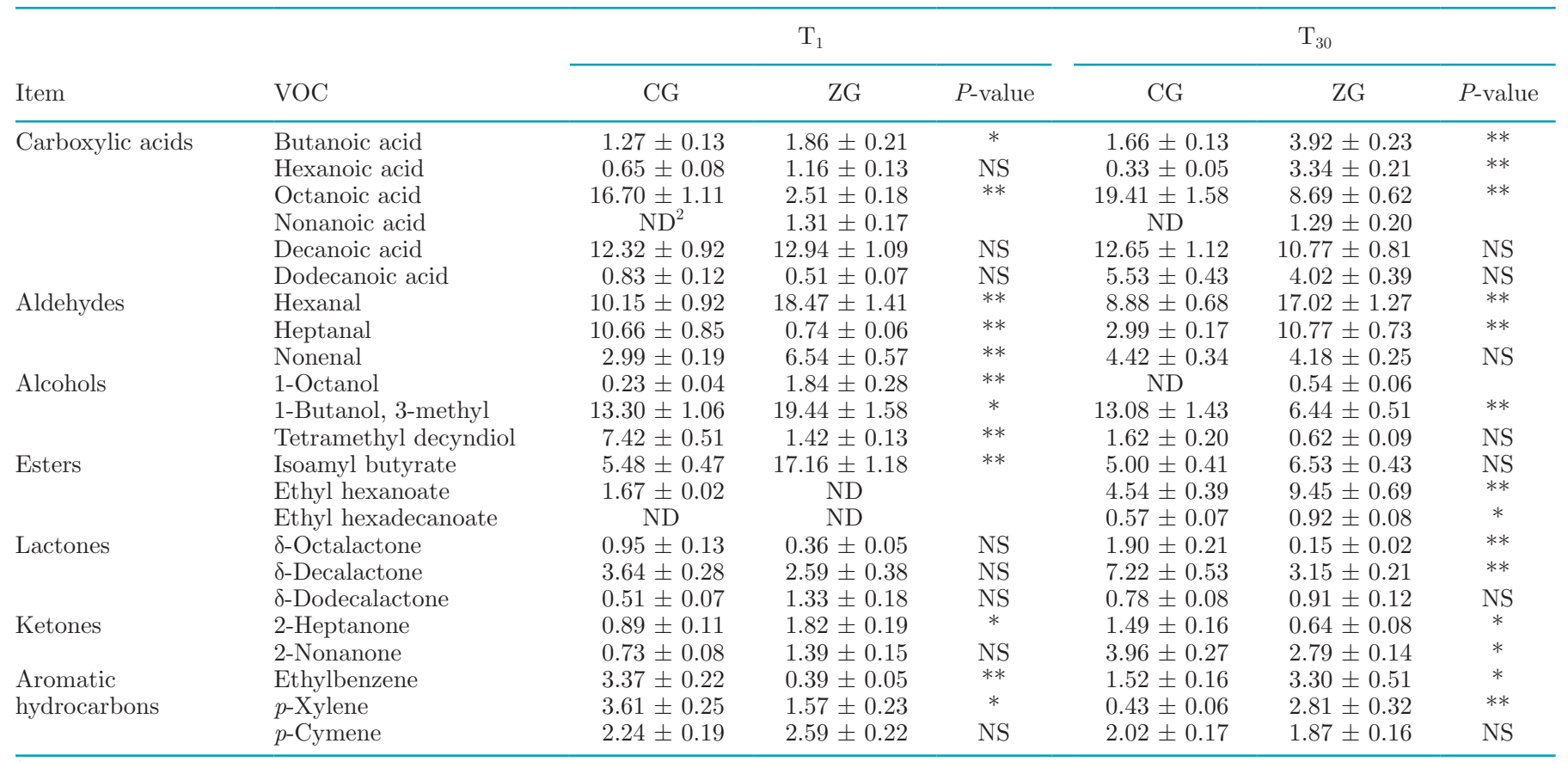

${ }^{1}$ Data are expressed as mean $\pm \mathrm{SD}$. Volatile compounds are expressed as percent of total volatile compounds.

${ }^{2} \mathrm{ND}=$ not detectable.

$* P<0.05 ; * * P<0.01$

tween the control and the experimental group. Despite the apparent contradiction, this finding is in agreement with what was reported by Pechová et al. (2006), which explained the phenomenon advancing the hypothesis of an impaired incidence of rumen acidosis in the herd before the start of the experiment. According to what was observed in milk, no differences were evidenced in the chemical-nutritional composition of cheese samples, both in relation to the feeding strategy and in relation to the ripening time. The only differences, as expected, concerned the increase in DM at the end of the ripening period.

The texture profile is an important characteristic used to differentiate many cheese varieties and is con- sidered by the consumer as a determinant of the overall quality of the product. With reference to our study, the dietary zinc supplementation induced a marked increase of cheese hardness, both at the beginning and at the end of the ripening period. The increase in this parameter is generally correlated with a decrease in fat content, which disagrees with our findings that did not show a reduction in fat in milk and cheese following zinc dietary intake (Bryant et al., 1995). At the same time, and probably in close correlation with hardness, a reduction of the Young module value as well as of gumminess was evidenced at $\mathrm{T}_{30}$.

The results of the present study showed the ability of zinc to influence the FA profile of cow milk and related

Table 6. Texture profile analysis of cheese samples after $1\left(\mathrm{~T}_{1}\right)$ and $30\left(\mathrm{~T}_{30}\right)$ d obtained from the control group $(\mathrm{CG})$ and zinc group $(\mathrm{ZG})^{1}$

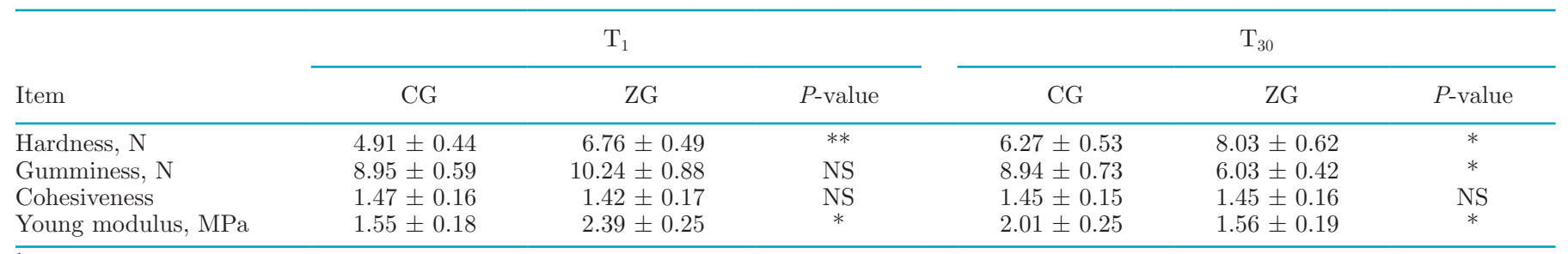

${ }^{1}$ Data are expressed as mean $\pm \mathrm{SD}$.

${ }^{*} P<0.05 ;{ }^{* *} P<0.01$. 
cheese. As reported by Nudda et al. (2005), the FA composition found in cheese reflects the composition observed in milk, suggesting that the observed variations in nutritional quality of milk, as a consequence of the experimental feeding strategy, are thereafter maintained in cheese. Dietary zinc positively affected the oleic acid level in milk and cheese. Because the diet administered to the ZG does not confer an additional source of oleic acid with respect to the $\mathrm{CG}$ diet, this result might be mainly related to the desaturation of stearic acid occurring in the mammary gland by stearoyl coenzyme A desaturase, a finding also supported by the C14:1/ C14:0 ratio, considered an index of $\Delta^{9}$-desaturation in the mammary gland (Mele et al., 2007). Stearoyl coenzyme A desaturase is an endoplasmic reticulum-bound enzyme that catalyzes the $\Delta^{9}$-desaturation of saturated fatty acyl-CoA (Miyazaki and Ntambi, 2003). Stearoyl coenzyme A desaturase is encoded by the stearoyl coenzyme A desaturase gene (Smith et al., 2006), whose expression is regulated by the sterol response element binding protein, a transcription factor synthesized as precursor that is attached to the endoplasmic reticulum. The proteolytic cleavage by site- 1 and site- 2 proteases allows the $\mathrm{N}$-terminal mature and active portion of sterol response element binding protein to reach the nucleus, inducing the expression of stearoyl coenzyme A desaturase and other lipogenic factors. Of particular interest for our work is the role of site- 2 protease, a metalloprotease that needs $\mathrm{Zn}$ to perform its catalytic function, justifying, at least in part, the highest concentration of oleic acid in milk and cheese obtained from ZG with respect to CG. Dietary zinc supplementation also seems to lead to an increase in milk and related cheese of vaccenic acid and CLA. The latter compound has 2 origin pathways; the first is the partial rumen biohydrogenation of linoleic acid, which is responsible for the production of a small proportion of CLA secreted in milk (Chilliard and Ferlay, 2004), and the second is its endogenous synthesis in the mammary gland starting from vaccenic acid (Lock and Bauman, 2004), which is responsible for about $60 \%$ of rumenic acid secretion in cow milk (Mosley et al., 2006). Conjugated linoleic acid is reported to perform an important antioxidant activity that protects bovine mammary epithelial cells from lipoperoxidation and mitigates the level of the reactive oxygen species, leading to an improvement of the mammary gland functionality (Basiricò et al., 2015, 2017). Ruminant products also represent the primary dietary source of CLA for humans. Several benefits of CLA for human health have been reported, and some important examples concern the modulation of the immune system (Song et al., 2005), the reduction of body fat accumulation (Evans et al., 2002), the enhancement of bone mineralization (Platt et al., 2007), and their potential activity of slowing the atherosclerosis development (Lock et al., 2004). Finally, MUFA and PUFA content increased in milk and cheese obtained after feeding enrichment with zinc, at the expense of SFA. As a direct consequence of this evidence, atherogenic and thrombogenic indices decreased in the ZG. In light of this, it could be argued that dietary zinc supplementation may increase nutritional value and health functionality of milk and related dairy products.

The evaluation of TBARS was used in this study as a marker for oxidative damage in cheese. Zinc has been reported to inhibit free radical lipid peroxidation in biological systems by serving, in several conditions, as a free radical scavenger (Fang et al., 2002). After only $1 \mathrm{~d}$ from the cheese-making, the TBA values of cheese obtained from the control group were significantly lower with respect to the experimental cheese. At the end of ripening $\left(\mathrm{T}_{30}\right)$, the TBA values increased, as expected, in $\mathrm{CG}$ cheese, but slightly decreased in ZG cheese, suggesting antioxidant protection provided by zinc. Kahraman and Ustunol (2012) reported similar behavior with zinc-fortified Cheddar cheese, where TBA values decreased over the ripening time. The same authors partially justified this behavior introducing the hypothesis of further reactions of MDA, which would therefore be underestimated.

The effect of dietary zinc on the aromatic profile evaluated in cheese seems very interesting. The most abundant class was represented by carboxylic acids, composed of acids from $\mathrm{C} 4$, butanoic, to $\mathrm{C} 12$, dodecanoic. Butanoic and hexanoic acids were present at higher concentrations in the ZG samples both at $\mathrm{T}_{1}(P<0.05)$ and after $30 \mathrm{~d}$ of ripening $(P<0.01)$ from the cheese-making. Butanoic and hexanoic acids are considered to be mainly involved in the determination of cheese flavor, giving origin to cheesy, rancid, and sweaty odors. The increased production of such compounds could be probably explained by an increase of lipolysis of the triglycerides by microbial and endogenous milk enzymes, resulting in an augmented release of FFA (Bertuzzi et al., 2018). The general increase of carboxylic acids in ripened cheese could be explained by the extent of starter cell autolysis, with the consequent release of peptidases and especially lipases that accelerate the lipolytic event (Collins et al., 2003). In this context, the cellular envelope appears as a physical barrier for the bacterial enzymes to reach the extracellular substrates and contribute to the development of cheese organoleptic properties. Over time, several peptidoglycan hydrolases, commonly named autolysins, have been characterized in Lactococcus lactis (Buist et al., 1995; Huard et al., 2003). These enzymes are 
characterized by an N-terminal domain, resembling a cell-wall-associated domain, a central catalytic domain, and a C-terminal domain containing a binding motif for $\mathrm{Zn}$, which is therefore an important cofactor in the mechanisms that lead to the lysis of the bacterial cells. Free fatty acids contribute to the formation of cheese flavor not only directly, but also giving origin to methyl ketones, secondary alcohols, aldehydes, lactones, and esters. Aldehydes represent the second group in order of abundance in our study, and seem to increase markedly during the ripening in ZG samples in which was evidenced a marked increase of hexanal and heptanal. These compounds are responsible for the "green grasslike" aromas, characterized by green, slightly fruity, lemon, and herbal notes (Bertuzzi et al., 2018). Isoamyl butyrate and ethyl hexanoate are the most represented esters in samples of ripened cheese obtained from the experimental group. These compounds are characterized by a low odor threshold and are generally associated with the sweet, fruity, and floral notes of surface-ripened cheese flavor (Niimi et al., 2015). Lactones tend to increase in CG samples during ripening, remaining almost unchanged in $\mathrm{ZG}$ cheese samples. These compounds are generally produced by a one-step transesterification reaction of hydroxylated FFA, which represent the main precursors. Hydroxylated FFA are released by lipolytic activities or by the heating process, and furthermore can be also produced from the catabolism of UFA by the action of microbial lipoxygenases and hydratases (Bertuzzi et al., 2018). Probably in the control group conditions persist that favor these enzymatic mechanisms with respect to those eventually present in ZG samples. A strange behavior is instead associated with alcohols and esters, whose synthesis mechanisms and contribution to the creation of the aromatic profile deserve further evaluation.

\section{CONCLUSIONS}

The present results suggest a positive role of zinc in improving the nutritional and nutraceutical properties of milk and corresponding cheese; moreover, important indications have been obtained in the direction of the improvement of animal welfare. The experimental feeding strategy may modify the quality of dairy products obtained from lactating dairy cows. The main finding concerns the increased amount of oleic acid, vaccenic acid, and CLA, at the expense of SFA, reflecting the fact that consumption of these products could have positive effects on human health. Besides of this, the aromatic profile of dairy products was also positively affected by dietary zinc intake. In this case it would, however, be necessary to verify whether these changes may have any effect on consumer acceptability.

\section{ACKNOWLEDGMENTS}

The authors are grateful to Ansape Company [Raiano (AQ), Italy] for the kind cooperation.

\section{REFERENCES}

AOAC. 1990. Official Methods of Analysis. Vol. 1. 15th ed. Association of Official Analytical Chemists, Arlington, VA.

AOAC International. 2000. Official Methods of Analysis. 17th ed. AOAC International, Washington, DC.

Armero, E., and C. Collar. 1997. Texture properties of formulated wheat doughs, relationships with dough and bread technological quality. Z. Lebensm. Unters Forsch. A 204:136-145.

Basiricò, L., P. Morera, D. Dipasquale, A. Tröscher, and U. Bernabucci. 2017. Comparison between conjugated linoleic acid and essential fatty acids in preventing oxidative stress in bovine mammary epithelial cells. J. Dairy Sci. 100:2299-2309.

Basiricò, L., P. Morera, D. Dipasquale, A. Tröscher, A. Serra, M. Mele, and U. Bernabucci. 2015. Conjugated linoleic acid isomers strongly improve the redox status of bovine mammary epithelial cells (BME-UV1). J. Dairy Sci. 98:7071-7082.

Bertuzzi, A. S., P. L. H. McSweeney, M. C. Rea, and K. N. Kilcawley 2018. Detection of volatile compounds of cheese and their contribution to the flavor profile of surface-ripened cheese. Compr. Rev. Food Sci. Food Saf. 17:371-390.

Bonaventura, P., G. Benedetti, F. Albarede, and P. Miossec. 2015 Zinc and its role in immunity and inflammation. Autoimmun. Rev. $14: 277-285$

Bryant, A., Z. Ustunol, and J. Steffe. 1995. Texture of Cheddar cheese as influenced by fat reduction. J. Food Sci. 60:1216-1219.

Buist, G., J. Kok, K. J. Leenhouts, M. Dabrowska, G. Venema, and A. J. Haandrikman. 1995. Molecular cloning and nucleotide sequence of the gene encoding the major peptidoglycan hydrolase of Lactococcus lactis, a muramidase needed for cell separation. J. Bacteriol. 177:1554-1563.

Castellani, F., A. Vitali, N. Bernardi, E. Marone, F. Palazzo, L. Grotta, and G. Martino. 2017. Dietary supplementation with dried olive pomace in dairy cows modifies the composition of fatty acids and the aromatic profile in milk and related cheese. J. Dairy Sci. 100:8658-8669.

Chilliard, Y., and A. Ferlay. 2004. Dietary lipids and forages interactions on cow and goat milk fatty acid composition and sensory properties. Reprod. Nutr. Dev. 44:467-492.

Coleman, J. E. 1998. Zinc enzymes. Curr. Opin. Chem. Biol. 2:222234.

Collins, Y. F., P. L. H. McSweeney, and M. G. Wilkinson. 2003. Lipolysis and free fatty acid catabolism in cheese: A review of current knowledge. Int. Dairy J. 13:841-866.

Cope, C. M., A. M. Mackenzie, D. Wilde, and L. A. Sinclair. 2009. Effects of level and form of dietary zinc on dairy cow performance and health. J. Dairy Sci. 92:2128-2135.

Domagała, J., M. Sady, T. Grega, H. Pustkowiak, and A. Florkiewicz. 2010. The influence of cheese type and fat extraction method on the content of conjugated linoleic acid. J. Food Compos. Anal $23: 238-243$.

Doreau, M., A. Meynadier, V. Fievez, and A. Ferlay. 2016. Ruminal metabolism of fatty acids: Modulation of polyunsaturated, conjugated, and trans fatty acids in meat and milk. Handbook of Lipids in Human Function. 521-542.

European Commission. 2003. Regulation (EC) No. 1831/2003 of the European Parliament and of the Council of 22 September 2003 on Additives for Use in Animal Nutrition.

European Economic Community. 1986. EEC Council Directive 86/609/EEC of 24 November 1986 on the approximation of laws, regulations and administrative provisions of the Member States regarding the protection of animals used for experimental and other scientific purposes. Off. J. L 358:1-28.

European Union. 2010. Directive 2010/63/EU of the European parliament and of the council of 22 September 2010 on the protection of 
animals used for scientific purposes. Accessed Apr. 3, 2015. http: //eur-lex.europa.eu/legal-content/EN/TXT/PDF/?uri=CELEX: 32010L0063\&from $=$ EN.

Evans, M., J. M. Brown, and M. K. McIntosh. 2002. Isomer-specific effects of conjugated linoleic acid (CLA) on adiposity and lipid metabolism. J. Nutr. Biochem. 13:508-516.

Fang, Y. Z., S. Yang, and G. Wu. 2002. Free radicals, antioxidants, and nutrition. Nutrition 18:872-879.

Grotta, L., F. Castellani, F. Palazzo, M. N. Haouet, and G. Martino. 2017. Treatment optimisation and sample preparation for the evaluation of lipid oxidation in various meats through TBARs assays before analysis. Food Anal. Methods 10:1870-1880.

Huard, C., G. Miranda, F. Wessner, A. Bolotin, J. Hansen, S. J. Foster, and M. P. Chapot-Chartier. 2003. Characterization of AcmB, an $\mathrm{N}$-acetylglucosaminidase autolysin from Lactococcus lactis. $\mathrm{Mi}-$ crobiology 149:695-705.

Kahraman, O., and Z. Ustunol. 2012. Effect of zinc fortification on Cheddar cheese quality. J. Dairy Sci. 95:2840-2847.

Kegley, E. B., and J. W. Spears. 1992. Performance and mineral metabolism of lambs as affected by source (oxide, sulfate, or methionine) and level of zinc. J. Anim. Sci. 70:302.

Kloubert, V., and L. Rink. 2015. Zinc as a micronutrient and its preventive role of oxidative damage in cells. Food Funct. 6:3195-3204.

Lock, A. L., and D. E. Bauman. 2004. Modifying milk fat composition of dairy cows to enhance fatty acids beneficial to human health. Lipids 39:1197-1206.

Lock, A. L., B. A. Corl, D. M. Barbano, D. E. Bauman, and C. Ip. 2004. The anticarcinogenic effect of trans-11 18:1 is dependent on its conversion to cis-9, trans-11 CLA by $\Delta 9$-desaturase in rats. J. Nutr. 134:2698-2704.

Mele, M., G. Conte, B. Castiglioni, S. Chessa, N. P. P. Macciotta, A. Serra, A. Buccioni, G. Pagnacco, and P. Secchiari. 2007. Stearoylcoenzyme A desaturase gene polymorphism and milk fatty acid composition in Italian Holsteins. J. Dairy Sci. 90:4458-4465.

Miller, W. J. 1970. Zinc nutrition of cattle: A review. J. Dairy Sci. $53: 1123-1135$

Miyazaki, M., and J. M. Ntambi. 2003. Role of stearoyl-coenzyme A desaturase in lipid metabolism. Prostaglandins Leukot. Essent. Fatty Acids 68:113-121.

Mosley, E. E., B. Shafii, P. J. Moate, and M. A. McGuire. 2006. Cis-9, trans-11 conjugated linoleic acid is synthesized directly from vaccenic acid in lactating dairy cattle. J. Nutr. 136:570-575.

Nascentes, C. C., M. A. Z. Arruda, A. R. A. Nogueira, and J. A. Nóbrega. 2004. Direct determination of $\mathrm{Cu}$ and $\mathrm{Zn}$ in fruit juices and bovine milk by thermospray flame furnace atomic absorption spectrometry. Talanta 64:912-917.

NRC. 2001. Nutrient Requirements of Dairy Cattle. Natl. Acad. Press, Washington, DC.

Nelder, J. A., and R. J. Baker. Generalized Linear Models. John Wiley \& Sons Inc. 1972.

Niimi, J., A. I. Eddy, A. R. Overington, P. Silcock, P. J. Bremer, and C. M. Delahunty. 2015. Sensory interactions between cheese aroma and taste. J. Sens. Stud. 30:247-257.

Nudda, A., M. A. McGuire, G. Battacone, and G. Pulina. 2005. Seasonal variation in conjugated linoleic acid and vaccenic acid in milk fat of sheep and its transfer to cheese and ricotta. J. Dairy Sci. 88:1311-1319.

Pechová, A., L. Pavlata, and E. Lokajová. 2006. Zinc supplementation and somatic cell count in milk of dairy cows. Acta Vet. Brno $75: 355-361$.

Platt, I., L. G. Rao, and A. El-Sohemy. 2007. Isomer-specific effects of conjugated linoleic acid on mineralized bone nodule formation from human osteoblast-like cells. Exp. Biol. Med. (Maywood) $232: 246-252$.

Rojas, L. X., L. R. M. C. Dowell, R. J. Cousins, F. G. Martin, N. S. Wilkinson, A. B. Johnson, and J. B. Velasquez. 1995. Relative bioavailability of two organic and two inorganic zinc sources fed to sheep. J. Anim. Sci. 73:1202-1207.

Salama, A. A. K., G. Caja, E. Albanell, X. Such, R. Casals, and J. Plaixats. 2003. Effects of dietary supplements of zinc-methionine on milk production, udder health and zinc metabolism in dairy goats. J. Dairy Res. 70:9-17.

Sandoval, M., P. R. Henry, R. C. Littell, R. J. Cousins, and C. B. Ammerman. 1997. Estimation of the relative bioavailability of zinc from inorganic zinc sources for sheep. Anim. Feed Sci. Technol. 66:223-235.

Singh, K. K., S. B. Maity, and A. Maity. 2018. Effect of nano zinc oxide on zinc bioavailability and blood biochemical changes in preruminant lambs. Indian J. Anim. Sci. 88:805-807.

Smith, S. B., D. K. Lunt, K. Y. Chung, C. B. Choi, R. K. Tume, and M. Zembayashi. 2006. Adiposity, fatty acid composition, and delta-9 desaturase activity during growth in beef cattle. Anim. Sci. J. $77: 478-486$

Sonawane, S. N., and S. P. Arora. 1976. Influence of zinc supplementation on rumen microbial protein synthesis in in vitro studies. Indian J. Anim. Sci. 46:13-18.

Song, H. J., I. Grant, D. Rotondo, I. Mohede, N. Sattar, S. D. Heys, and K. W. J. Wahle. 2005. Effect of CLA supplementation on immune function in young healthy volunteers. Eur. J. Clin. Nutr. 59:508-517.

Spears, J. W. 1989. Zinc methionine for ruminants: Relative bioavailability of zinc in lambs and effects on growth and performance of growing heifers. J. Anim. Sci. 67:835-843.

Spears, J. W. 1996. Organic trace minerals in ruminant nutrition. Anim. Feed Sci. Technol. 58:151-163.

Tofalo, R., M. Schirone, G. Fasoli, G. Perpetuini, F. Patrignani, A. C. Manetta, R. Lanciotti, A. Corsetti, G. Martino, and G. Suzzi. 2015. Influence of pig rennet on proteolysis, organic acids content and microbiota of Pecorino di Farindola, a traditional Italian ewe's raw milk cheese. Food Chem. 175:121-127.

Ulbricht, T. L. V., and D. A. T. Southgate. 1991. Coronary heart disease: Seven dietary factors. Lancet 338:985-992.

Van Soest, P. J., J. B. Robertson, and B. A. Lewis. 1991. Methods for dietary fiber, neutral detergent fiber, and nonstarch polysaccharides in relation to animal nutrition. J. Dairy Sci. 74:3583-3597.

Wang, R. L., J. G. Liang, L. Lu, L. Y. Zhang, S. F. Li, and X. G. Luo. 2013. Effect of zinc source on performance, zinc status, immune response, and rumen fermentation of lactating cows. Biol. Trace Elem. Res. 152:16-24. 